\title{
Rhenium distribution and behaviour in the salinity gradient of a highly stratified estuary and pristine riverine waters
}

Elvira bura-Nakić ( $\nabla$ ebnakic@irb.hr)

Institut Ruđer Bošković: Institut Ruder Boskovic https://orcid.org/0000-0001-9544-1586

Lucija Knežević

Institut Ruđer Bošković: Institut Ruder Boskovic

Jelena Mandić

Institut za Oceanografiju i Ribarstvo

Ana-Marija Cindrić

Institut Ruđer Bošković: Institut Ruder Boskovic

Dario Omanović

Institut Ruđer Bošković: Institut Ruder Boskovic

\section{Research Article}

Keywords: dissolved rhenium (DRe), salinity gradient, estuary waters, freshwater

Posted Date: April 27th, 2021

DOI: https://doi.org/10.21203/rs.3.rs-344179/v1

License: (c) (i) This work is licensed under a Creative Commons Attribution 4.0 International License. Read Full License

Version of Record: A version of this preprint was published at Archives of Environmental Contamination and Toxicology on August 6th, 2021. See the published version at https://doi.org/10.1007/s00244-02100876-6. 


\section{Abstract}

The abundance and distribution of dissolved $\operatorname{Re}(\mathrm{DRe})$ has been determined in the freshwater part of the Krka River (Croatia), draining the karstic carbonate landscape, as well as in the salinity gradient of its highly stratified estuary. Due to low DRe concentration, the batch procedure consisting of preconcentration step using an anion exchange resin (Dovex) and analysis of DRe in 8 M HNO 3 eluate using a high resolution inductively coupled plasma mass spectrometry (HR ICP-MS) was adopted. Due to the potential inconsistent recoveries, ranging from $60 \%$ to $87 \%$, the quantification was performed by using the isotope dilution (ID) technique. The DRe concentration in the Krka River basically increased in the downstream direction, with the $6.2 \mathrm{pM}$ at the spring site, reaching $11.9 \mathrm{pM}$ before the estuarine region. The weathering of the surrounding carbonate lithology is assumed as the source of natural Re. The two specific anomalies were registered: a strong increase in DRe concentration due to the anthropogenic input near the town of Knin $(27.5 \mathrm{pM})$ and a decrease at downstream site caused by the subterranean input of freshwater of the Zrmanja River leading to relatively low DRe concentration (8.5 pM). In the estuarine segment, a near-conservative behavior of DRe was found in the salinity gradient of the upper surface layer, with the DRe concentration ranging from 18 to $38 \mathrm{pM}$. An anthropogenic supply was suggested within the estuarine segment close to the urban area causing a small positive deviation from the conservative line. In the bottom seawater layer, a minor decrease of DRe concentration in the most upstream estuarine regions was evidenced, implying a potential weak scavenging of Re.

\section{Full Text}

This preprint is available for download as a PDF.

\section{Figures}




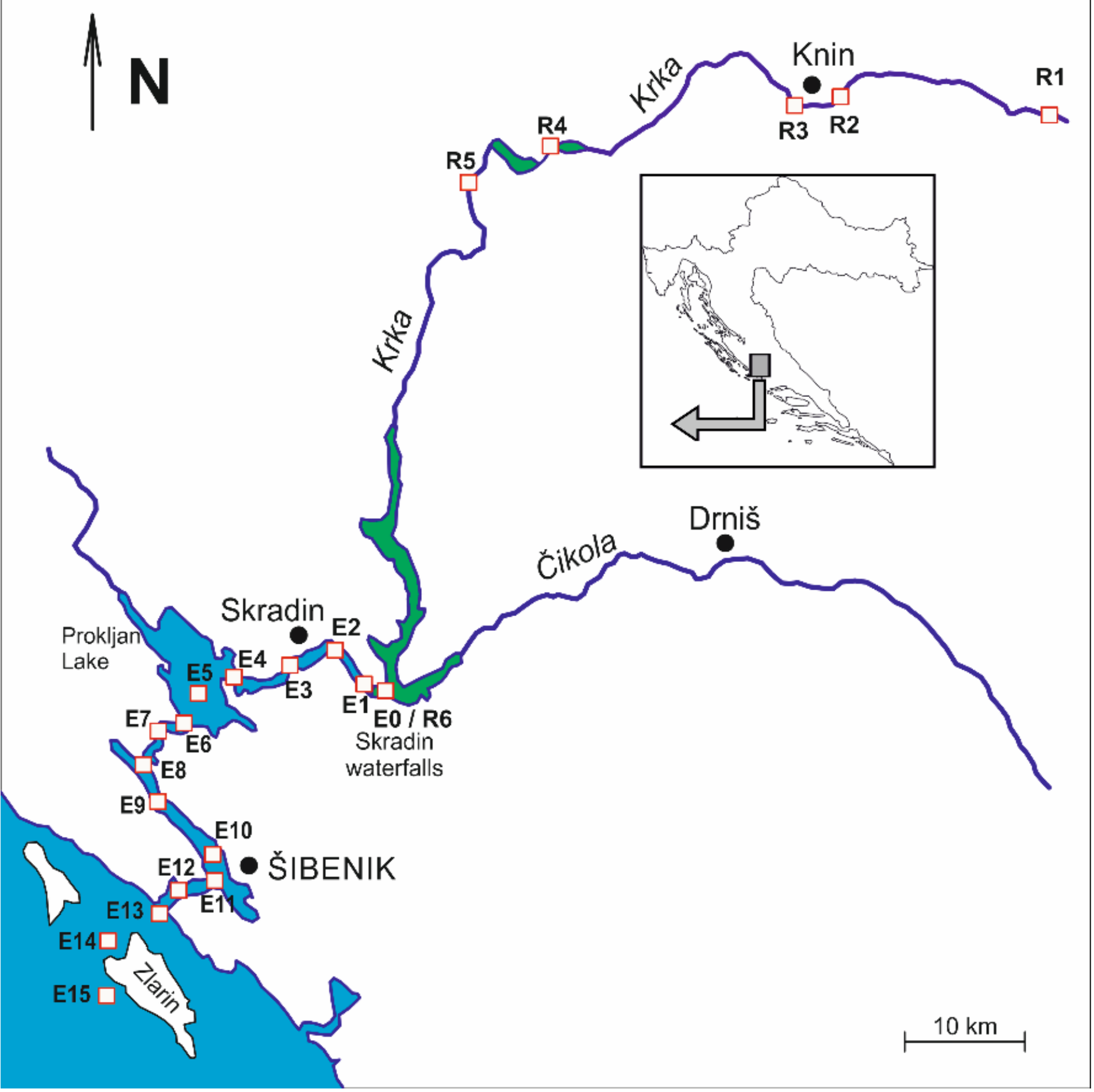

Figure 1

Map of the Krka River as well as estuary with indicated locations of sampling sites (open red squares). Note: The designations employed and the presentation of the material on this map do not imply the expression of any opinion whatsoever on the part of Research Square concerning the legal status of any country, territory, city or area or of its authorities, or concerning the delimitation of its frontiers or boundaries. This map has been provided by the authors. 


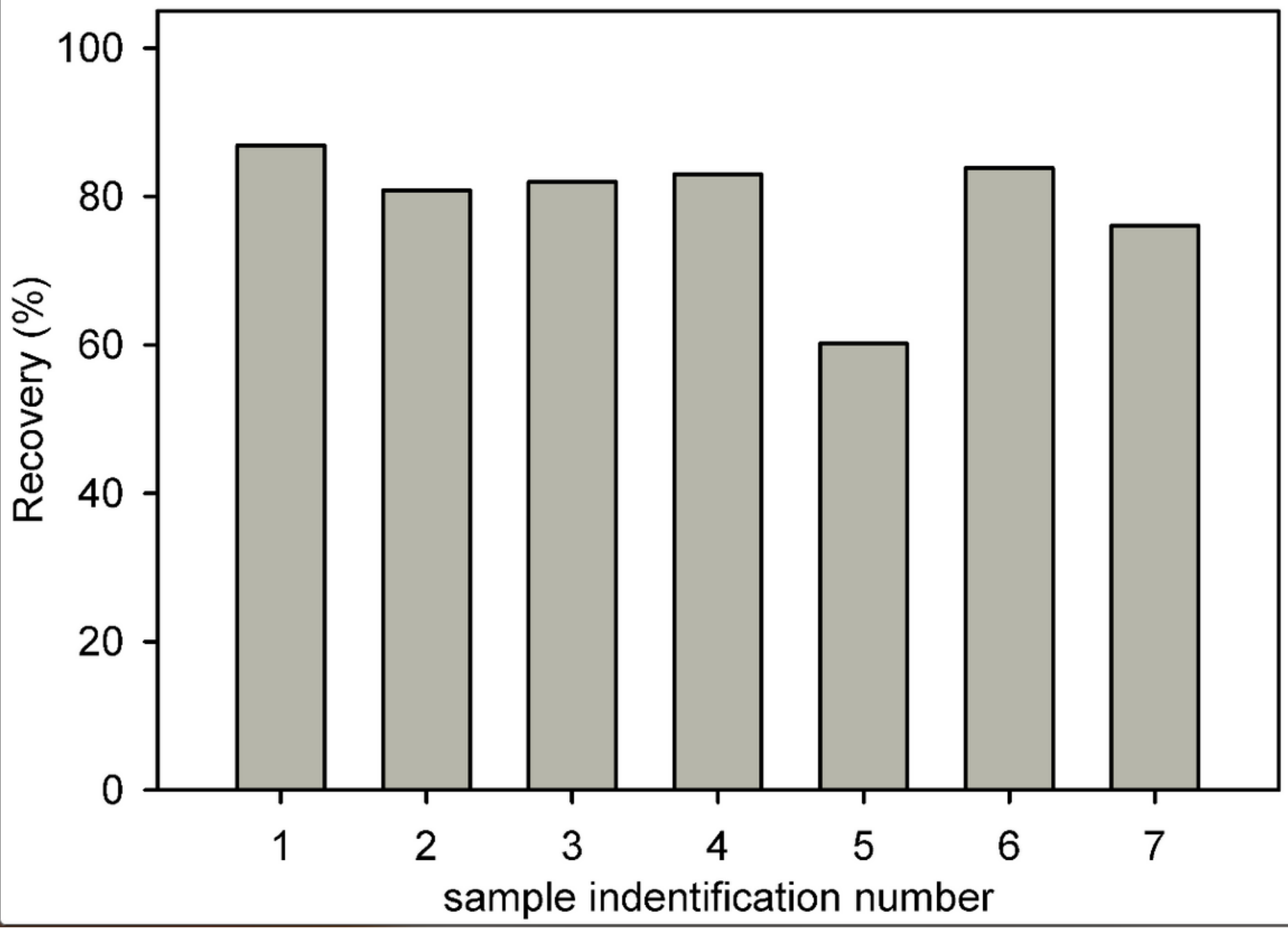

Figure 2

Recoveries in \% for: 1) MQ water + 53 pM Re ICP-MS standard; 2) MQ water + 107 pM Re ICP-MS standard; 3) MQ water + 214 pM Re ICP-MS standard; 4) Krka River sample + 53 pM Re ICP-MS standard; 5) Adriatic seawater sample + 53 pM Re ICP-MS standard; 6) $0.55 \mathrm{M} \mathrm{NaCl}+53 \mathrm{pM} \mathrm{Re} \mathrm{ICP-MS} \mathrm{standard;}$ 7) $0.55 \mathrm{M} \mathrm{NaCl}+53 \mathrm{pM}$ Re ICP-MS standard. In all cases except in the case of sample number 7 the final $\mathrm{HCl}$ concentration was $1 \mathrm{M}$. In the case of sample number 7 the final $\mathrm{HCl}$ concentration was $0.5 \mathrm{M}$. 


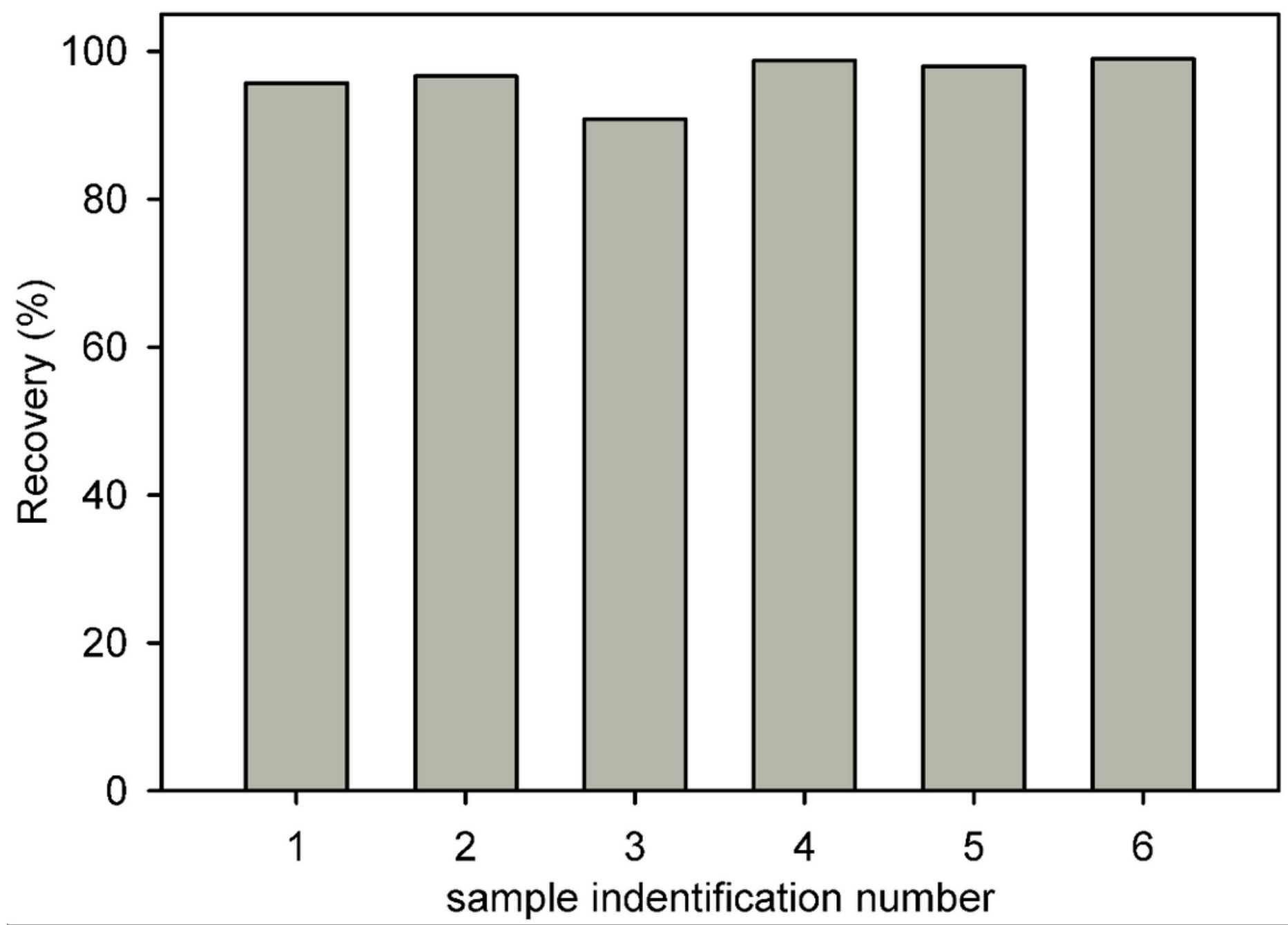

Figure 3

Recoveries in \% for: 1) MQ water + 53 pM Re ICP-MS standard + 53 pM ID standard; 2) MQ and $0.55 \mathrm{M}$ $\mathrm{NaCl}$ water + 53 pM Re ICP-MS standard + 53 pM ID standard; 3) MQ water + 107 pM Re ICP-MS standard + 107 pM ID standard; 4) MQ water + 214 pM Re ICP-MS standard + 214 pM ID standard; 5) MQ water and $0.55 \mathrm{M} \mathrm{NaCl}+53 \mathrm{pM}$ Re ICP-MS standard + $53 \mathrm{pM}$ ID standard; 6) MQ water and $0.55 \mathrm{M} \mathrm{NaCl}+107$ pM Re ICP-MS standard + 107 pM ID standard. In all samples the final $\mathrm{HCl}$ concentration was $1 \mathrm{M}$. 


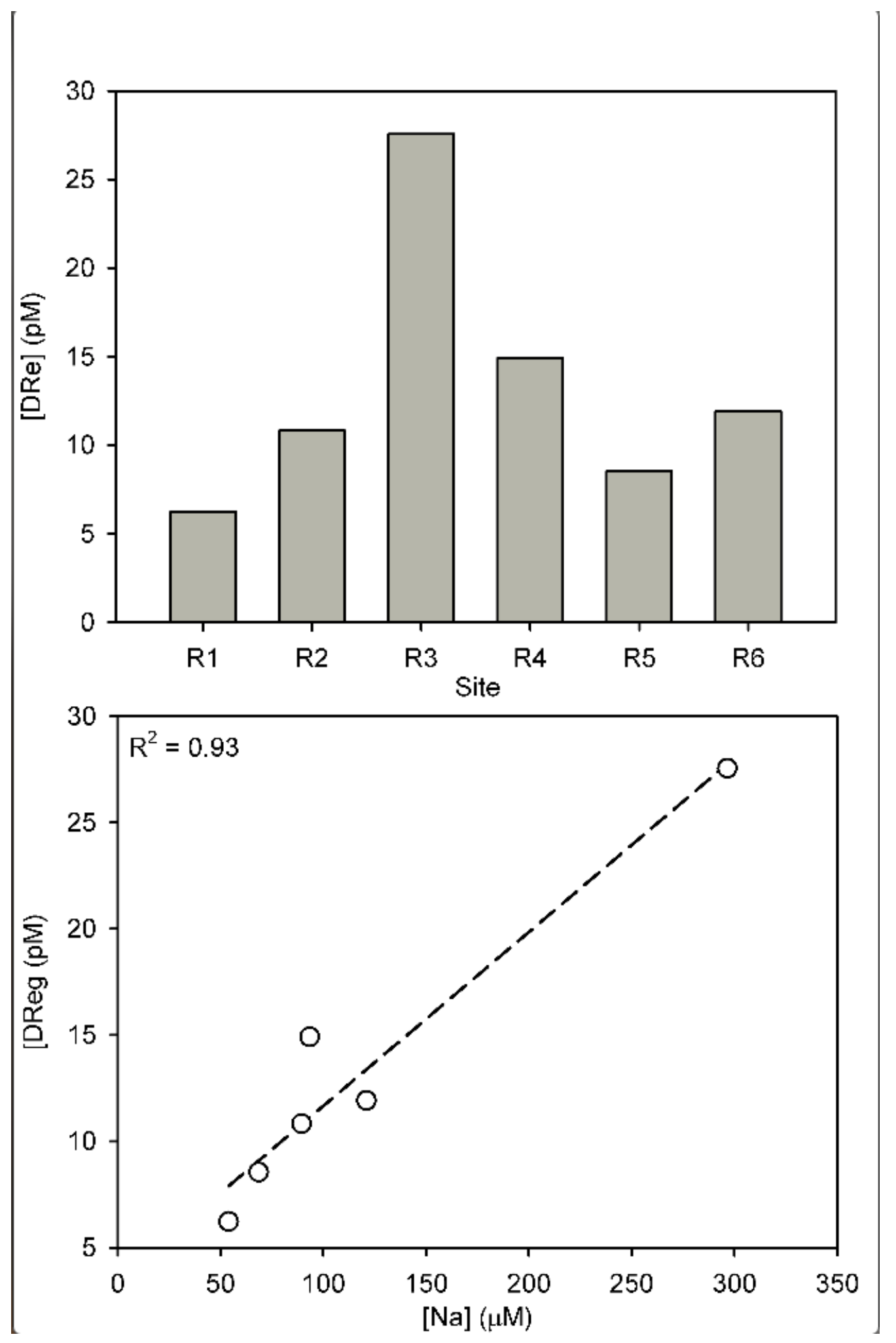

Figure 4

The dissolved Re concentration along the Krka River and [DRe] vs [Na] correlation for R1 to R6 sites. 

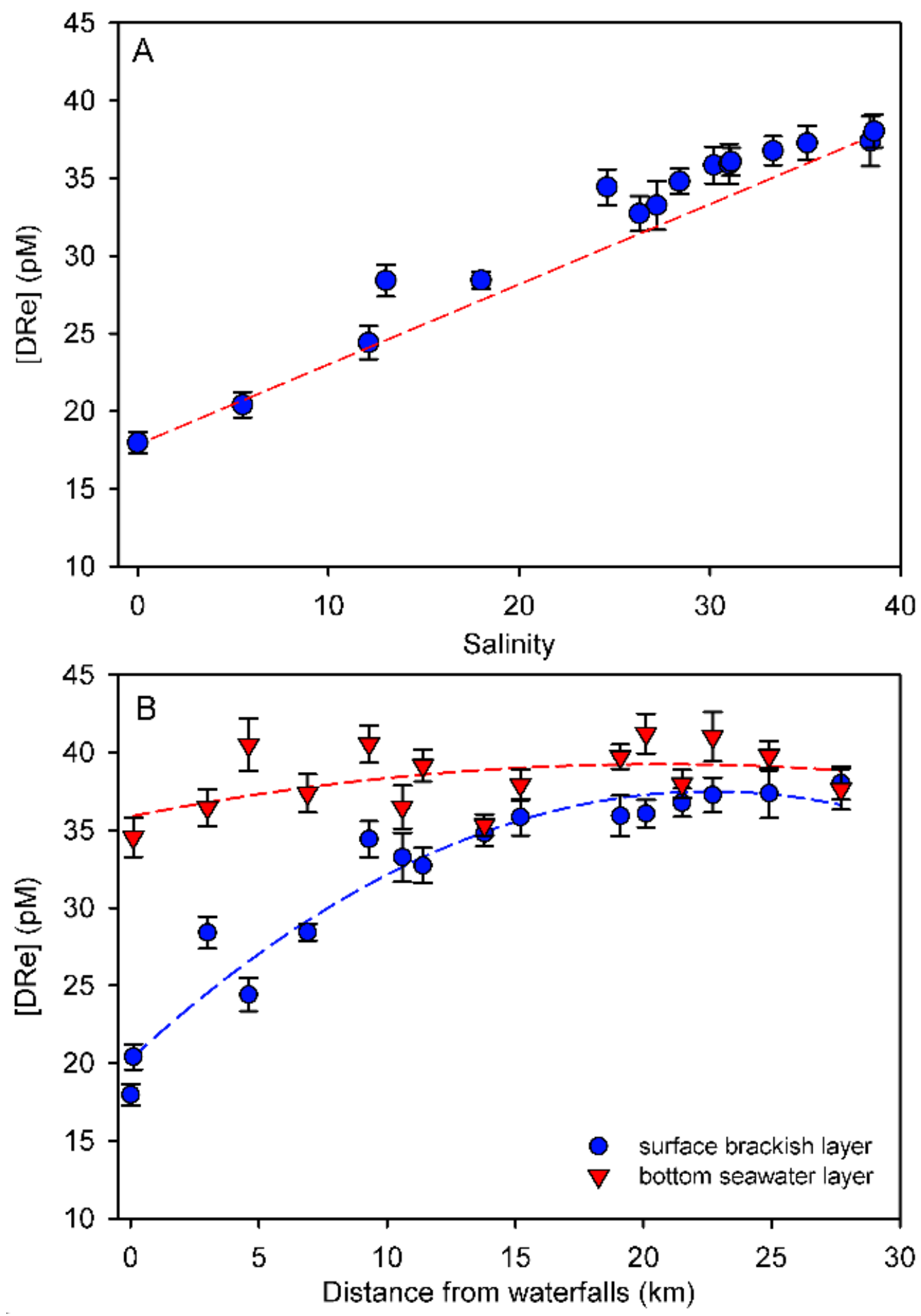

\section{Figure 5}

A) Distribution of DRe along the salinity gradient in the Krka River estuary and B) distribution of DRe in the surface brackish and bottom seawater layer in relation to distance. Dashed line in plot (A) represents a theoretical dilution line, while in plot (B) they represent a projected trend ( 2 nd order polynomial) for the measured DRe. 